\title{
A comparative study of fertility preferences of Nigerian female migrants and non-migrants in Benin City, Nigeria.
}

\author{
Osazuwa Peter ${ }^{1} \&$ Ugal David $^{2}$ \\ ${ }^{1}$ Department of Sociology, University of Ibadan, \\ Ibadan, Oyo State, Nigeria. \\ ${ }^{2}$ Department of Sociology, Federal University, Lafia, Nigeria. \\ Email:opeters2000@yahoo.com
}

\begin{abstract}
Context/Background: Whereas a large body of literature has already focused on fertility and migration at destination area, relatively few studies have examined fertility in association with return-migration at country of origin. This study is an investigation of the association between international return-migrants and non- migrants' fertility preferences among women in Benin City, Nigeria.

Data Sources/Methods: Data were collected from 760 migrants and non-migrants through multistage sampling technique and were analysed employing descriptive statistics, Chi-square, correlation and Ordinal regression.

Findings: Returnees' migration experience $\left(X^{2}=212.971, d f=4, p<.001\right)$ and length of stay abroad $\left(X^{2}\right.$ $=15.899, \mathrm{df}=6, \mathrm{p}<.050)$ and socioeconomic status $\left(\mathrm{X}^{2}=8.674, \mathrm{df}=4, \mathrm{p}>.050\right)$ were associated with higher fertility preferences. Non-migrants' fertility preferences were lower ( 3.89 children average) than those of migrants (4.14). Migrants who stayed longer abroad were 1.06 times more likely to prefer larger family size compared with those who stayed for shorter periods.

Conclusion: Migration should not be discouraged in order to achieve the ideal fertility aspiration of the country's population policy.
\end{abstract}

Keywords: Fertility preference, female migrants, non-migrants, migration, destination, Benin City.

\section{Introduction}

Migration is as old as humankind and has always been an essential component of the human situation. The volume of global migration has increased significantly since 2000 (Ajaero \& De Wet, 2017; UN-DESA, 2015). Traditional male-dominated-short-to-longdistance migratory streams in West Africa are becoming increasingly feminised (Adepoju, 2005). 'Women constituted 50 per cent of global migratory flows, though the proportion varies significantly by country and could be as high as 70 to 80 per cent in some cases" (UNESCO, 2006: 2, Liang and Ma 2004).

In recent decades, Nigeria has become a sending country (IOM, 1995). According to the National Population Commission (NPC 2004), it is estimated that more than 2 million Nigerians would have emigrated to Europe and the United States alone. However, a great number in the Diaspora are willing to return. Available evidence on the origin of Nigerian immigrants in Europe and the United States indicates that the majority of them come from the relatively less developed and densely populated southern provinces (Haas, 2006). The Igbo from the southeast and the Yoruba from the southwest; and to a lesser extent, the Edo (Benin) and the Ogoni ethnic groups seem to constitute the majority of Nigerian migrants in the United Kingdom (Hernandez-Coss et al, 2006).

Migration has been and still remains the least researched component of population dynamics. According to Onokerhoraye (1993: 137), "we know comparatively less about migration than mortality and fertility as factors affecting population dynamics". In this relative neglect of a sub-field of demography (migration) lies marginal interest in return migration; its influence on fertility and population distribution, particularly among women. Studies on returnmigration have mostly been linked to economic issues and problems than to demographic issues. Where return movement was the primary focus of scholars, little was done to examine systematically, the phenomenon in its relationship with fertility preferences particularly among females in developing countries. (Omondi \& Ayiemba, 2003; Ohagi, \& Isiugo-Abanihe, 1998; Osili, 2007; Okali et al, 200 I).

While empirical studies on return-migration have started to accumulate, its connection with fertility preferences is still lacking or at best limited. Consequently, international return-migration and non-migrants and its connection with fertility 
preferences have remained a neglected aspect of migration research and nowhere is this neglect more apparent than in Benin City where international migration and return is high. This neglect invariably calls to mind the need to explore this elusive aspect of migration study. The investigation of the nexus between return-migration and female non-migrants fertility preferences, having international returnees as focus, is germane in bridging this identified gap in knowledge. Failure to do this will slow down population growth as captured in the National Population Policy (Odimegwu et al, 20 I7).

Generally, the study examined a comparative analysis of fertility preferences among migrants and non-migrants in Benin City, Nigeria. Specifically, the study sought to examine the influence of socioeconomic status of migrants and non-migrants on fertility preferences among women; to examine the association between migration and non-migration status and fertility preferences; to investigate the link between length of stay at destination country and fertility preferences of return-migrants and to determine the nature of relationship between migrants and non-migrants 'fertility preferences and outcomes.

\section{Theoretical framework}

\section{Acculturation and diffusionism}

This study is essentially concerned with the adoption of cultural trait than its transmission. The study takes adoption to be synonymous with taking up, acquiring, receiving, while on the other hand, it takes transmission to be akin to spreading or giving of cultural trait. Acculturation theory provides assumptions for the adoption of culture than its broader parent, diffusionism. Diffusionism is concerned with cultural transmission or spreading. Titiev (1959:446) captured this distinction clearly when he defined diffusion as the "spread" of a cultural item from its place of origin to other places. For instance, from returnees to people at the place of origin and 'vice versa'. A more expanded definition depicts diffusion as the process by which discrete culture traits are "transferred" from one society to another, through migration, trade, war, or other contact (Winthrop, 1991:82). On the other hand, acculturation is a process whereby immigrant (minority) groups are expected to "adopt" the dominant culture of the host country (Farley, 1992). It is the process of "acquiring" culture traits as a result of contact (The Encyclopedia of Social and Cultural Anthropology, 1996). With regard to this study, culture is used broadly to include among other things, the value system of the receiving country such as small family size norm and preference.
Acculturation will usually result in an increased similarity between the two cultures in contact. This type of change may be reciprocal. Very often however, the process is asymmetrical and the result is the (usually partial) absorption of one culture into the other (Kroeber, 1948). The researchers have adopted acculturation theory because the subject matter of the study is directed at the receiver (female return-migrants) than at the spreader/transmitter/source. The research, however, makes a case for what happens to acquired fertility preferences on return and the processes through which culture is transmitted at destination areas. Therefore, diffusionism is applied to extend acculturation theory in providing explanation on migrants' interaction with the society at the place of origin and destination.

Acculturation theory suggests that contact between societies whether hostile or friendly, intense or slight, can bring about changes (Farley, 1992: 607). Amado M. Padilla \& William Perez (http://www.stanford.edu/ apadilla/PadillaPerez03a. pdf) believe that acculturation is a social process that occurs in a context in which newcomers and members of the host culture are in dynamic contact with one another. Newcomers, regardless of their heritage, culture and whether they are sojourners, refugees, or voluntary immigrants, must in one form or another adapt to their new cultural environment (Ward et al., 200I). The social identities they develop in the new environment influence social cognitions that in turn guide their UK behaviour such as the clothes they wear, the food they eat, the people with whom they associate, the values to which they adhere, and the strategies used to acclimatize to the new culture and its people.

Fapohunda and Todaro (1988) observed that African family structure shapes spousal perceptions of child-related process and affects individual reproductive decision-making. On migration, migrants develop what has been aptly termed 'cultural competence' in response to the new social environment they find themselves. Cultural competence is simply the learned ability to function in a culture in a manner that is congruent with the values, beliefs, customs, mannerisms, and language of the majority of members of the host culture. In essence, migrants must gain acceptance by adopting the dominant way of life at destination area. Most often, migrants do so at the expense of their own culture. Through constant interaction, they evolve a different social identity at destination, that is, individual behaviour tends to reflect larger societal units (Tajfel \& Turner, 1986). In other words, overarching societal structures such as groups, organizations, cultures, and individuals' identification 
with these collective units guide internal structures and processes.

\section{Conceptual framework}

Below is a diagrammatic representation of connections among variables.

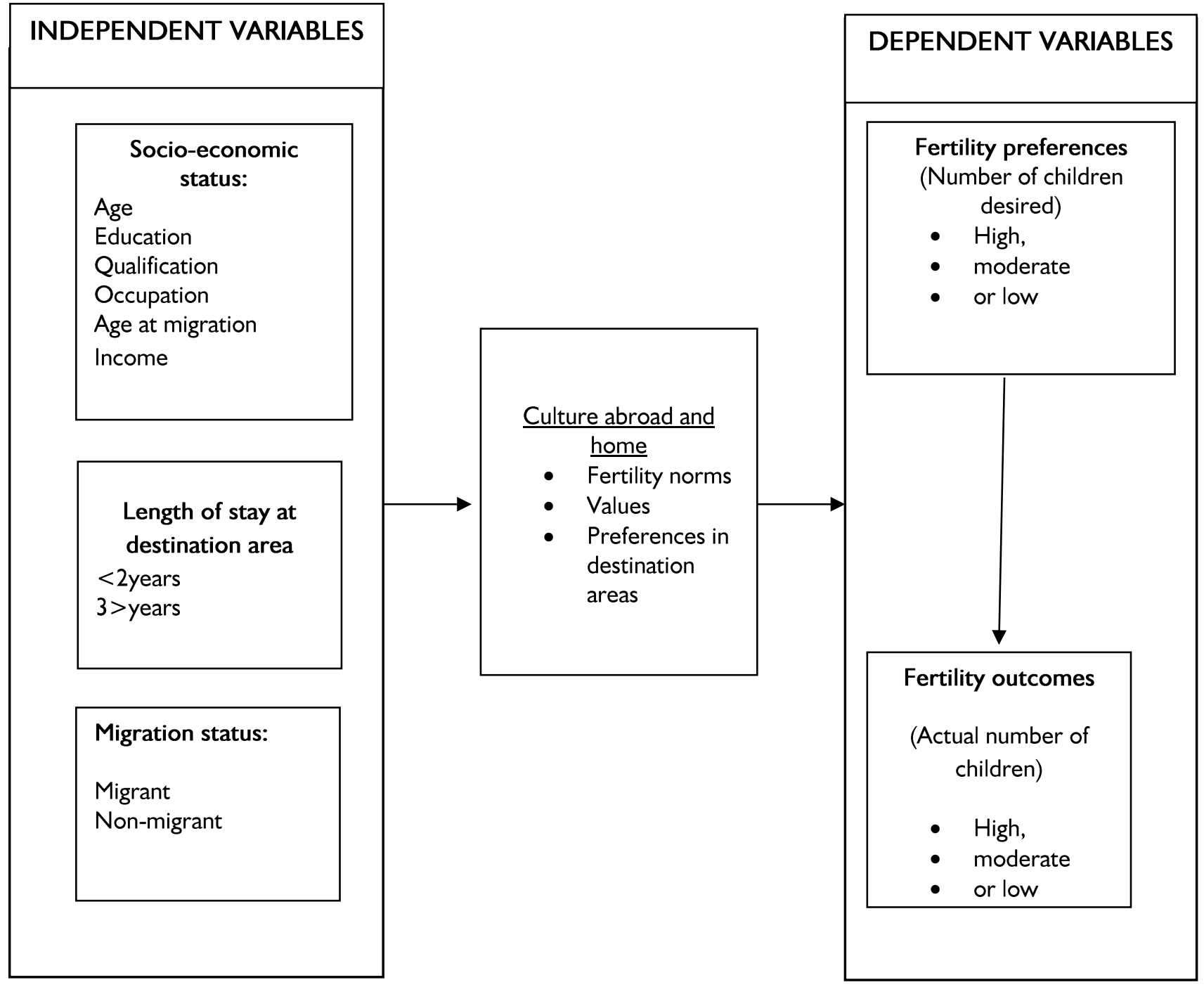

Authors: 2017

Figure I: Migration/non-migration and fertility behaviour

From the conceptual framework, the dependent variables- fertility preference and outcomes - are influenced by socio economic status and length of stay abroad. Length of migrant stay at place of destination is depicted in the diagram to influence exposure to prevailing fertility norm/value before ultimately influencing migrants' fertility preferences and outcomes. In other words, the connection between length of stay and fertility preferences and outcomes is not direct at destination. For example, the longer the length of stay of a migrant, the more likely the influence of culture on him. This may occur as a result of continuous interaction with the society; the people, institutions, value system, mass media among others. Age at migration also influences has repercussion for preferences and fertility outcomes.

The arrow between preference and outcome suggests that actual reproductive behaviour can be predicted from subject's fertility preferences. Preference is measured by the number of children desired and fertility by the actual number of children ever had (dead or alive). Fertility preferences and actual fertility are categorized into high ( $5+$ children), moderate ( $3-4$ children) and low ( $2>$ children) to enable the researcher make comparison. Condition/reason for return is classified into forced returnees- for migrants whose returns are due to repatriation, deportation and expulsion, on one hand, and voluntary returnees, on the other. intensity of interaction at the destination area which 


\section{Data source and methods}

The study adopted the quantitative technique to generate data. A total of 296 migrants and 464 nonmigrants 'respondents were sampled. Non-migrants were selected through multi-stage sampling procedure. Copies of the survey questionnaire were administered to migrants and non-migrants. Female returnees were divided into two categories: voluntary $(210)$ and forced (86) returnees. At the time of this study, there was no evidence that voluntary returnees were organizing themselves at the (Edo) state level nor was there any reliable data on this group of female returnees.

According to Haas (2006) 'Reliable or even approximate data on Nigerian migration is generally lacking'. Consequently, a household survey was conducted using the Enumeration Areas (EAs) demarcated for the 2006 population census for the three Local Government Areas (LGAs) used in Benin City, to identify voluntary returnees. These local government areas are Ipoba-oka, Oredo and Eghor having 2,009, I,510 and 901 EAs respectively. This decision was based on the realization that female international returnees were strongly concentrated in the State of Edo, particularly in Benin City (Carling, 2005). The city has a population of I, I 47, I 88 people (http://en.wikipedia.org/wiki/Benin City).

Ten EAs were selected systematically from each of the two LGAs (Ipoba-oka and Oredo LGA) and nine EAs from the third (Eghor LGA), making 29 EAs for the three LGAs. A household sample frame was drawn up, from which eligible respondents were identified and systematically selected. Two hundred and ten voluntary returnees were systematically (hat and draw) selected from the sample frame for interview based on one per household.

The forced returnees were in-mates of three nongovernmental organizations committed to rehabilitating and integrating female victims of trafficking in Benin City. They are namely: Idia Renaissance (IR) with 50 in-mates, Committee for the Support of the Dignity of Women (COSUDOW) with 26 in-mates and National Agency for the Prohibition of Traffic in Persons (NAPTIP) housing 30 in-mates. While all in-mates were targeted, only 43, 16 and 27 in-mates respectively were available for interview during the period of the research. These respondents were contacted on days of their regular meetings, workshops and seminars after securing permission from their administrators. Given the nature of their return, which is usually negative, forced returnees were a difficult - to - reach - group in Benin City. Most of them were returned on account of illegal migration and prostitution. In total, 86 forced female returnees were identified and interviewed.
We carried out the analysis at three levels: univariate, bi-variate and multivariate. Using the Statistical Package for Social Sciences (SPSS), information collected was analysed by both descriptive and inferential statistics, including frequency, simple percentage, mean and cross tabulation to describe the socio-economic characteristics of respondents; while chi-square, and regression were used for bivariate and multivariate analyses. Respondents' fertility preferences were regrouped into high, medium and low on the basis of the calculated percentiles. Respondents' length of stay abroad was also re-grouped into long, medium and short-term migration. Respondents were asked to select all the family planning methods they knew and those they had used from a list of thirteen modern methods. They were also free to indicate other methods that were not on the list. The mean of methods known and methods used were compared for migrants and non-migrants.

The dependent variable, that is, fertility preference, is the actual number of children a woman desires. It is the number of children a woman of childbearing age desires in the study area. Age at migration is the age at which respondent emigrated. Length of stay abroad is the total number of months or years that a migrant continuously lived abroad. Respondents whose length of stay abroad was less than three months were not included in this study. In the study, ideal number of children is used as a measure of fertility preference. .

Because the dependent variables of the study (fertility preferences) were classify into low $(<2$ children), moderate ( 3 - 4 children) and high (5> children), ordinal regression (ordered logit) was employed for analysis at the multi-variate level. The coefficient and odds ratio $\beta$ (Exp) of relevant variables were used along with their significant level to predict the likelihood of having low or high fertility preferences. The odd ratio value that is greater than I implies that a factor increases the preference of respondents' number of children.

\section{Results}

Table I presents descriptive characteristics of respondents in the study and also makes a distinction between background variables for returnees and non-migrants. All the 760 women surveyed were within reproductive age, while a majority was between the ages of 20 and 39. The mean age of respondents was $33.5 \pm 10.9$ years. Non-migrant respondents were slightly older than returnees, with only about 2 years difference in their ages. Although more women $(57.5 \%)$ were married among the nonmigrant group, married respondents were the highest 
(52.5\%) for both groups. This makes fertility comparison justifiable.

A large number of the returnees were single $(40.5 \%)$. The figure is particularly high when compared with that of non-migrants and the total for all respondents (33.6\% and $36.3 \%$ respectively). Except for only $2.4 \%$ of them who had no schooling, all women in the sample had some level of formal education. A large number of the respondents had secondary education $(33.0 \%$ for non-migrants and $29.6 \%$ for all respondents). Returnees constituted $37.2 \%$ of those who had first degree. When respondents' education is regrouped into primary, secondary and tertiary, the result shows that there were more migrant women having tertiary education $(68.6 \%)$ than their non- migrant group counterparts $(58.4 \%)$.

Table I: Socio-Socioeconomic Characteristics and mean fertility preference of Respondents

$\begin{array}{llll}\text { Characteristics } & \text { Migrants\% } & \text { Non Migrants\% } & \text { Percent* }\end{array}$

Age

$<=19$

20-24

$25-29$

30-34

$35-39$

40-44

$45-49$

$=>50$ years

Marital status

Single

Married

Divorced

Separated

Widowed

Educational qualification

No schooling

Primary

Secondary

Tertiary(total)

- NCE/OND

- HND/University

- M.Sc./Ph.D.

Others

Religion

Christianity

Islam

Traditional

Others

Occupation

Unemployed

Student

Manual worker

Farmer

Trader

Teacher

Civil servant

Business

Other specify

Monthly Income

$$
<\mathrm{NI}, 000
$$

$\mathrm{NI}, 00 \mathrm{I}-\mathrm{N} 4,999$

N5, $000-N 9,999$
2.7

18.6

25.3

17.2

15.5

10.1

5.7

4.7

40.5

44.6

3.0

6.4

5.4

1.7

4.4

24.3

68.6

26.7

37.2

4.7

I.0

89.9

4.7

4.4

1.0

II. 8

21.6

4.4

0.3

3.7

4.4

15.9

34.1

3.7

5.2

8.2

II.6
3.0

16.2

18.1

21.1

14.7

8.8

7.8

10.3

33.6

57.5

2.6

2.4

3.9

2.8

5.6

33.0

58.4

30.2

25.0

3.2

0.2

91.4

5.0

3.7

0.0

9.7

16.8

0.9

0.6

9.3

6.9

II. 0

41.4

3.4

4.0

7.3

II.6
2.9

17.1

20.9

19.6

15.0

9.3

7.0

8.2

36.3

52.5

2.8

3.9

4.5

2.4

5.1

29.6

63.5

28.8

27.7

3.8

0.5

90.8

4.9

3.9

0.4

10.5

18.7

2.2

0.5

7.1

5.9

12.9

38.6

3.6

4.5

7.7

11.6 
NIO, $000 \&>$

74.9

77.1

76.3

\begin{tabular}{lccc}
\hline Characteristics & Mean for Migrants & Mean for Non Migrants & Mean for all \\
\hline Ideal number of children & $(4.14)$ & & $(3.89)$ \\
Actual number of children & $(2.40)$ & $(2.53)$ & $(4.02)$ \\
Parents' number of children & $(7.70)$ & $(9.26)$ & $(8.48)$ \\
Parents' ideal No. of children & $(6.9)$ & $(8.85)$ & $(7.88)$ \\
Mean Age & $(32.46)$ & $(34.60)$ & $(33.53)$ \\
Respondents (N) $\quad 760$ & & &
\end{tabular}

()$=$ Not percent, actual number. ${ }^{*}=$ Percent for all respondents. $=\mathrm{N}=150.00$ is equivalent to $\$ 1.00$ as at 2010

With respect to religion, migrant and non-migrant respondents were remarkably similar; majority (90.8\%) in the two groups were Christians. Respondents whose occupation was business were largest and were generally more in each category than those in other occupations. They were only followed by respondents who were students. From the income distribution, over $50 \%$ of women surveyed were living above 2 dollars per day.

Parents' family size preference and actual number of children ever had are close and high. The Demographic and Health Survey DHS (2008) puts Africa's fertility preference and outcome at 7.88 and 8.42 children, respectively. Similar pattern is noticed in the data above. A closer look at the figures on parents' family size preference and their actual number of children reveals that parents' actual number of children is higher than their preferred family size by 0.6 children. Conversely, respondents' actual number of children is lower than their ideal number of children by 1.55 children (perhaps, owing to uncompleted fecundity). Respondents' ideal number of children is shown to be lower than ideal national fertility for Nigeria, which is put at 6.I (NPC \& ICF Macro, 2009), while those of their parents is about I child higher.

Clearly, while returnees and non-migrants show similarity on many of the identified background characteristics, they are, however, different on some very salient variables that have been shown to have profound bearing on fertility behaviours. Those identified here are educational pursuit, (which can delay fertility) and influence fertility preference, (which has been variously demonstrated to impact fertility outcomes) (Isiugo-Abanihe, 2003). As indicated in Table I, female migrants tend to be of relatively higher educational background than their counterparts at the point of origin, but lower than their counterparts at the destination (Attiya 1976; CAPMAS 1989).

\section{Age at migration and fertility preferences}

The literature on immigrant assimilation has long recognized age at immigration as a decisive variable for understanding the process of assimilation of immigrants in many socio-economic dimensions (Chiswick, 1991). In addition, age at immigration may also matter if there are critical ages at which individuals learn a particular behaviour or skills that are crucial for assimilation (Bleakley and Chin, 2010; Schaafsma and Sweetman, 200I). In the case of fertility, there could be an additional effect, if there is a particular age at which cultural norms regarding fertility are already formed (for instance, the onset of puberty). In this study, despite the fact that respondents' migration was directed at destination with comparatively lower fertility, the chi-square test does not show a significant $(P$-value 0.70$)$ relationship with respect to age at migration and fertility preferences at $5 \%$ level of significance as indicated in Table 2.

Table 2: Age at migration and fertility preferences among returnees Fertility Preferences level

\begin{tabular}{|c|c|c|c|c|c|c|c|c|}
\hline Characteristic Low & Moc & ate & h Total* & $\mathrm{X}^{2} \mathrm{cal}$ & Df & $P$ & & \\
\hline Age at migration & & & & & & 8.674 & & $070 *$ \\
\hline Up tol 5 & (I7)30.9\% & (17)30.9\% & $(21) 38.2 \%$ & $(55$ & $100 \%$ & & & \\
\hline $16-25$ & (73)39.7\% & (7I)38.6\% & (40)21.7\% & $(18$ & $100 \%$ & & & \\
\hline Abv-25 & (I5) $26.3 \%$ & (26)45.6\% & (I6)28.1\% & $(57$ & $100 \%$ & & & \\
\hline
\end{tabular}




$\begin{array}{lllll}\text { Total } & (\mathrm{I} 05) 35.5 \% & (\mathrm{I} \mid 4) 38.5 \% & (77) 26.0 \% & (296) 100 \%\end{array}$

() frequency. * Total frequency for all categories of respondents. ${ }^{* *}$ sig at $5 \%,{ }^{* * *}$ sig at $10 \%$.

This finding does not seem to confirm previous research on the correspondence between age at migration and fertility preference. Most of these studies assumed that age at immigration and the level of acculturation have an effect on immigrants achieved proficiency of the host culture and how well migrants learn the target culture (Masgoret \& Gardner 1999 and Stevens, 1999). The earlier migration takes place, the better proficiency is achieved (Stevens, G. 1999: 555). In addition, it is very likely that the younger migrants will build, in time, a higher number of important social relationships with members of the majority and, therefore, increase their opportunities to interact and acculturate to small family norms at destination area. Early arrival affords the person more time in the host country and increases the likelihood that the young migrants may attend school and understand early in life the rules and institutions governing the socioeconomic life of the receiving country.

The test did not reveal any significant difference in fertility preference according to age at migration. This is perhaps because, many female migrants in the study were adults, most of whom were already married and have formed close friendships before migrating, and probably do not have such a strong motivation for learning and adopting new culture including small family practices (Burnam et al. 1987: 94). Research suggests that the older a person becomes, the harder the acquisition of a new culture becomes. This is because when migration takes place at older age, maturational and social constraints have a greater effect, and full native-like proficiency seems to become impossible (Birdsong 1992). Therefore, behaviour will resemble more of the culture of place of origin than those of destination area.

\section{Migration status and fertility preference}

To determine the relative association between migration and change in fertility preference, returnees' fertility preference at destination was cross-tabulated with their preference on return (at origin). A significant (P-value 0.00 ) relationship was observed from chi-square test, as shown in Table 3, implying that, returnees' preferences on return are similar to their preferences when they were abroad.

Similarly, from Table $3 b$, before migration, the mean fertility preference of migrant respondents was 4 children. At destination, migrant's family size preference declined to 3.29 children, perhaps owing to adaptation to the small family size preference prevalent at destination (Kulu, 2003) or owing to the disruption effects associated with territorial movements/relocation or as a result of both influences working simultaneously in reshaping migrants' fertility preferences.

On migrants' return to place of origin, returnees' family size preference was 3.31 children, which indicates a slight increase in the number of children desired by returnees at destination but still lower than the number desired before migration to destination area. As shown in the chi-square result in Table 3, 76.5\% of female returnees who preferred smaller family size at destination also maintained this preference on return to origin.

Table 3: Family size preference at destination and at origin (return)

A

Family size preference level on return Chi-square

\begin{tabular}{|c|c|c|c|c|c|c|}
\hline Characteristic Low & Mod & Hig & Total* & $\mathrm{X}^{2} \mathrm{cal}$ & Df & $P$ \\
\hline $\begin{array}{c}\text { Preference level at } \mathrm{d} \\
\text { Low }\end{array}$ & $\begin{array}{l}\text { stination } \\
(78) 76.5 \%\end{array}$ & (23) $22.5 \%$ & (I) $1.0 \%$ & $\begin{array}{r}2 / 2.791 \\
(102) 100 \%\end{array}$ & 4 & $.000 * *$ \\
\hline Moderate & (20) $12.0 \%$ & (I34)80.7\% & $(12) 7.2 \%$ & (166) $100 \%$ & & \\
\hline High & (4) $\mid 4.3 \%$ & (6) $21.4 \%$ & (I8)64.3\% & (28) $100 \%$ & & \\
\hline Total & $(102) 34.5 \%$ & (I63)55. \%। & $(3 \mid) 10.5 \%$ & (296) $100 \%$ & & \\
\hline
\end{tabular}

B:

Mean fertility preference of migrants

\section{Characteristics}

Mean Mean Mean

http://aps.journals.ac.za 


$\begin{array}{llll}\text { Ideal number of children } & 4 \text { children } & 3.29 \text { children } & 3.3 \text { I children } \\ \text { Respondents }(N) & 296 & \end{array}$

\section{C: Correlation Analysis of fertility preference and fertility outcome}

$\begin{array}{ll}\text { Pearson Correlation } & .687 \\ \text { Sig. (two-tailed) } & .000 * * \\ \text { Respondents (N) } & 296\end{array}$

() frequency. * Total frequency for all categories of respondents. ** sig at $5 \%$,

In addition, from Table 3c, correlation test reveals a significant (the correlation coefficient of 0.687 is significant at $1 \%$ level, positive and moderately strong) relationship between fertility preferences of non-migrants and fertility preference of migrants. This suggests that migration is related to and is a factor in changes in returnees' current family size preference.

However, migrants, (as noted earlier) have a mean preference of 3.31 children, which suggests low fertility preferences for female migrants, as indicated in Table 3. This boost may be a result of family pressures to have a particular sex of child, usually male, to sustain family name. This applies more to female migrants who already have children. This is not an important influence in the reproductive behaviours of citizens of more economically developed countries, where migration is mostly directed.

It is argued that children of a particular sex are often desired to provide certain utilities, such as financial, social, or psychological benefits. In less developed countries, for example, sons are presumed to have greater economic net utility than daughters, since male offspring are better able to provide assistance in agriculture and to serve as the traditional social security system (Hank \& Kohler, 2003). In a patrilineal society, like Benin City, sons are valued for continuing the family name. Daughters, on the other hand, should be more reliable in providing old-age assistance. In addition, they are frequently desired as help with household tasks or with the care of younger siblings. Brockmann (200I) contends that even modernization does not necessarily "neutralize" sex preferences.

Therefore, migrants who hitherto were not perturbed by the sex of children at destination can be pushed to reorient themselves as such, thereby accounting for preference for larger family size. The finding here does not confirm diffusionism. According to this theory, migrants are expected to diffuse acquired fertility values at the place of origin after their return. On the contrary, the migrants were influenced instead by the dominant fertility behaviour at origin.

\section{Length of stay and fertility preferences}

Table 4 shows the chi-square tests on the relationship between migrants' length of stay at destination and migrants' fertility preferences; this association is significant at $5 \%$. This shows that length of stay abroad increases the total number of children a migrant will prefer. This result suggests that the effect of disruption (social, economic and psychological costs of residential relocation) reduces with time. In other words, longer stay implies upwards adjustment of the preference level against shorter stay. This is perhaps because migrants who are initially separated from spouses because of migration (in the short run) are reunited again and, thus, changes the whole fertility calculus.

Table 4: Length of stay and family size preference of returnees

\begin{tabular}{|c|c|c|c|c|c|c|c|}
\hline & \multicolumn{4}{|c|}{ Fertility preferences } & \multicolumn{3}{|c|}{ Chi-square } \\
\hline & Low & Moderate & High & Total $*$ & & $\mathrm{X}^{2} \mathrm{cal}$ & Df \\
\hline Length of stay & & & & & 15.899 & 6 & $.014 * *$ \\
\hline Up to 2 & (47) $43.9 \%$ & $(40) 37.4 \%$ & (20) $\mid 8.7 \%$ & $(107)$ & & & \\
\hline $3-4$ & (24) $32.9 \%$ & (35) $47.9 \%$ & (14) $19.2 \%$ & (73) & & & \\
\hline $5-6$ & (13) $26.5 \%$ & (19)38.8\% & (I7)34.7\% & (49) & & & \\
\hline Abv. 6 & $(21) 31.3 \%$ & (20)29.9\% & (26) $38.8 \%$ & (67) & & & \\
\hline
\end{tabular}


() frequency. ${ }^{*}$ Total frequency for all categories of respondents. ${ }^{* * *}$ sig at $1 \%, \quad * *$ sig at $5 \%$,

As the length of stay of female migrants abroad increases, preference for larger family size increases, as indicated in Table 4. The interruption in childbearing caused by migration may be followed by accelerated fertility among migrants (Sharma, 1992). From studies based on the effect of migration and fertility of migrants to developed countries, evidence has been found that a temporary disruption is followed by rising fertility (Jasso \& Rosenzweig, 1990; Blau, 1992).

In the short run, fertility preference may follow the disruption model. This model postulates that there is an initial drop in couples' fertility preference around the time of migration (explained in part by moving costs) and fertility preference which later follows the adaptation approach (Blau 1992; Kahn 1994). In other words, the two models (disruption and adaptation) can be combined and it may be possible to observe an initial drop in fertility preference at the time of immigration, followed by a subsequent rise in fertility preference bypassing that of natives and a gradual decline to converge to the host country's levels. Ram and George, (1990) and $\mathrm{Ng}$ and Nault, (1997) observed evidence of shortlived fertility disruption upon immigration and quick convergence to domestic-born fertility levels along with socio-economic assimilation.
Similarly, contrary to predictions of the disruption and adaptation hypotheses, Lindstrom and Saucedo (2007) observed that women's migration to the United States does not appear to disrupt the timing of birth and, therefore, their reproductive aspirations. A possible explanation for this is that couples are anxious to have a birth in the United States, with the expectation that the child's right to US citizenship will open a future route to legal immigration status for the parents. In other words, policy plays an important role in migrants' fertility preferences or decisions. Evidence from other countries suggests that a higher risk of birth among immigrant women is because of the fact that migration and family formation are often connected events (Andersson 2004, Milewski 2007). However, fertility slows considerably compared to childbearing in place of origin (Lindstrom \& Saucedom, 2007).

Fertility preferences among return-migrants and non-migrants

Preference for a large family size among returnees was slightly higher than among non-migrants, as shown by the T-Test in Table 5 .

Table 5: Mean difference of fertility size preferences between returnees and non-migrants

N Mean $\quad$ Std. deviation $\quad$ Std. Error Mean

Respondents

$\begin{array}{lllll}\text { Migrants } & 296 & 4.14 & 1.786 & .104 \\ \text { Non-Migrants } & 464 & 3.89 & 1.663 & .077\end{array}$

B: Mean difference of fertility size outcome between migrants and non-migrants

\begin{tabular}{llllllc} 
& $\mathrm{N}$ & Mean & Mean difference & $\mathrm{t}$ & $\mathrm{df}$ & $\mathrm{P}$ \\
\hline Respondents & & & & & & .626 \\
$\quad$ Migrants & 296 & 2.04 & -.137 & -.682 & 758 & \\
Non-Migrants & 464 & 2.53 & -.137 & -.672 & 604.396 &
\end{tabular}

() frequency. $*$ Total frequency for all categories of respondents. ** sig at $5 \%$

Surprisingly, a fertility size preference for returnees (4. 14 children) was higher than that of non-migrants (3.89 children on the average). This is in direct contrast to the common observation in a number of 4299 previous studies (particularly adaptation and acculturation studies) which uniformly reveal that the fertility preferences of migrants are significantly lower than those of non-migrants. However, the reverse is http://aps.journals.ac.za 
the case when the actual fertility size (outcomes) between returnee women and non-migrant women are compared. The average number of children for returnees was 2.04 children, while that of nonmigrants was 2.53 children, as shown in Table 5B.

The difference is not, however, significant at $P$ value of .626 , as indicated in the same Table $5 B$. This means that the migrants and non-migrants captured in the study were relatively similar on this variable. Despite this, a difference (0.137), although slight, exists in their actual reproductive outcome, as indicated in the independent sample tests. This difference results from migration experience. This result is similar to that of Lee (20II), who investigated the same situation in Cameroon. He observes that the fertility differential between migrants and non-migrants was very small in Cameroon when compared with that of Korea and Mexico. He, however, warns that 'the lack of clear fertility differentials between migrants and nonmigrants, which are the result of the unique cultural and bio-social parameters of African fertility, does not imply a weak fertility adaptation effect, as also noted in this study.

Migration shapes values and attitudes. Even domestic norms, such as greater emphasis on girls' schooling and higher age of marriage, can filter from the destination country to the sending society (Fargues, 2007). Migration decision is also an integral part of family planning decisions and leads to differences in fertility rates among migrants and non- migrants (Singley \& Landale 1998, Fargues 2007). Some studies find migrants' fertility to resemble more closely that of natives at destination, either owing to social adaptation or self-selection of migrants by fertility preferences (Kulu 2005, Chattopadhyay et al. 2006). Although according to Ratha et al (20II), there can be regional variations.

Ordinal Regression analysis showing factors influencing fertility preferences.

In this section of the paper, age at migration, length of stay abroad and condition of migrants' return were tested against fertility preference to see their various impacts. Selected background variables were also regressed and relative influence determined.

Table 6 is on the determinants of the family size preference by all returnee respondents. Ordinal regression was used. In this table, 3 models are presented, namely:

Model I tests for the impact of status of Migration, Condition of return-Forced [voluntary] R

Model 2 sequentially includes and tests for the marginal impact of: Parent's number of children and ideal number of children abroad.

Lastly, model 3 controls for: socio-economic status

The ODD RATIO statistics are reported. Odd ratio value that is greater than I implies that a factor increases the outcome of respondents' number of children.

Table 6: Ordinal Regression analysis showing factors influencing family size preference for all migrants and non-migrants.

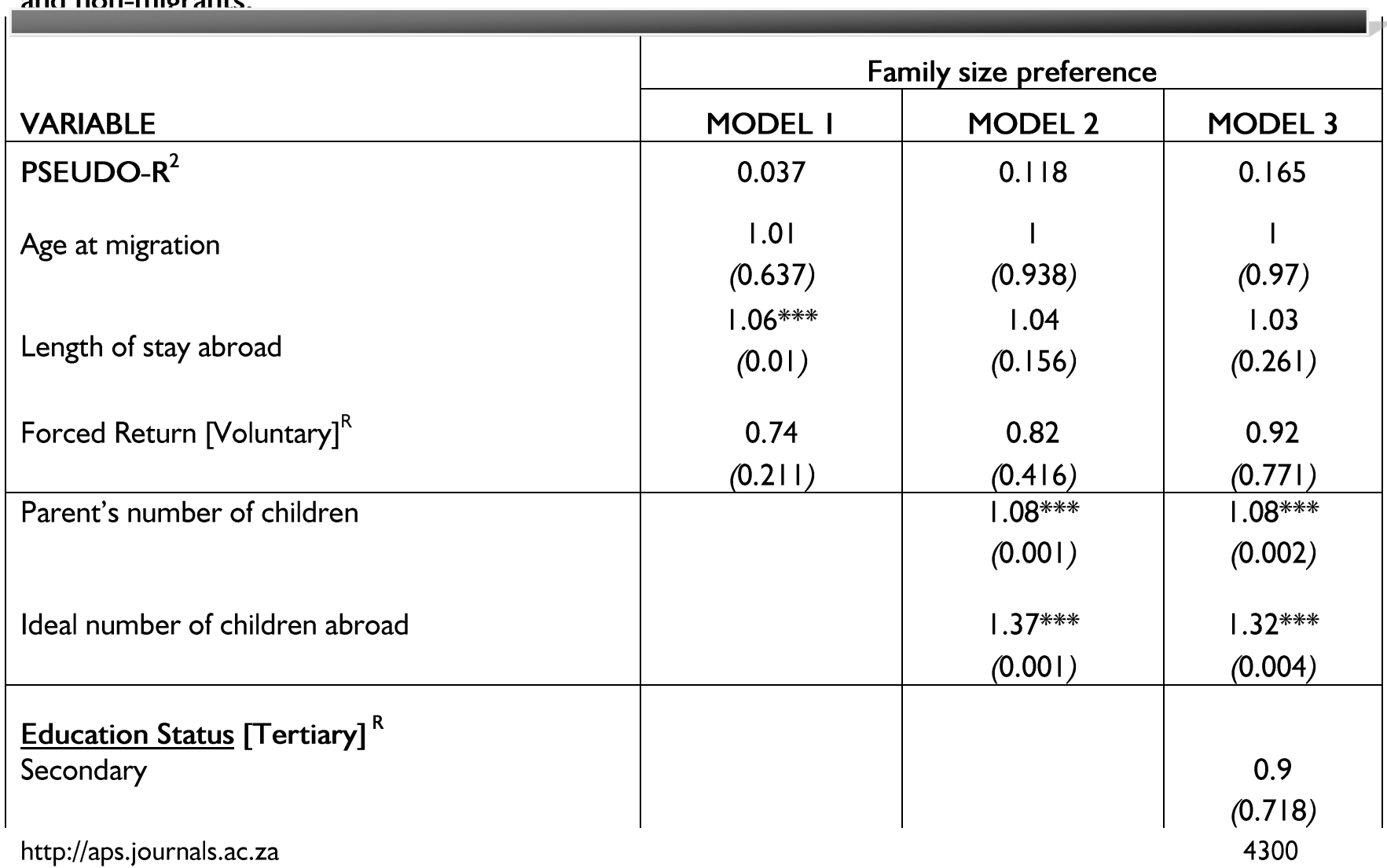


Up to primary

Occupation [Govt. Work] ${ }^{\mathrm{R}}$

Unemployed

Student

Artisans

Business/trading

Marital Status [Married] ${ }^{R}$

Single

Once married

Income $[N 10,000 \& \text { above }]^{R}$

Less than N5, 000

N5, 000- N I0, 000

R: reference category $*{ }^{* * *}, * * *$ implies significance at $10 \%, 5 \%$ and $1 \%$ respectively

Model I of Table 6 shows that for all migrant respondents, length of stay abroad plays the most important role in predicting $(7 \%)$ fertility preference of return-migrant women. The positive relationship between length of stay abroad and fertility preference suggests that a unit increase in the family size preference at destination area will induce a $7 \%$ probability that female migrants will change their fertility preference in a similar manner. In other words, female migrants who stayed longer abroad are more likely to have similar ideal fertility with those at destination area than migrants who stayed for a shorter period.

Model 2 indicates that parents' fertility outcome and the ideal family size at destination area play important roles as determinants of all returnees' family size preference by $8 \%$ and $37 \%$ respectively. These factors reduce the impact of length of stay. This implies that migrants' length of stay abroad is not the major influence in preference change. Both socialization (parents' fertility preferences) and adaptation factors (fertility preference at destination) simultaneously influence migrants' fertility preferences. This result corroborates some findings in the literature that social and cultural norms operating in the current residential environment influence childbearing intentions and outcomes (Caldwell 1982). However, according to Gabrielli et al (2007), the difference between socialization and adaptation would be one of timing, with adaptation being manifest relatively soon and socialization taking longer, usually working across generations. It is important to note that socialization variable (that is ideal number of children abroad) provides the largest explanatory power. Exposure to different sociocultural norms will lead to changes in fertility behaviour, such that the migrant population's fertility rate will ultimately converge with that of the locals at destination (Kahn 1994, Mayer and Riphahn 2000).

Model 3 shows that when background variables are controlled, parents' fertility outcome maintains its significance at P-value 0.002 , allowing for a $5 \%$ error. Ideal fertility abroad retains its explanatory power, though by $32 \%$. Marital status is the mediating variable. Economic factor, such as income, does not seem to play any mediating role in this relationship. This is contrary to findings in some studies espousing economic causation. From the economic perspective, in contrast to the sociological, socialization and adaptation are seen as being linked to household income and the cost of having children. Differences in wages for men, women, and children, the constraints of living costs and income in the destination area, and the variation in employment and educational opportunities change the real costs of childbearing, thus altering fertility behaviour (Becker 198I). 


\section{Discussion}

This study is related to two major demographic variables: fertility preference and female returnmigration. There are numerous studies on each. Few studies examine the two. Even fewer treat the two together; this study belongs to this group. One can claim that,by relating these variables, the important and underlying dynamics of childbearing patterns can be revealed, at least, in terms of preference for size of a family. This consideration points out the importance of studying the determinants of fertility behaviour of women and, in particular, the relationship between international migration and fertility, especially considering an origin country, such as Nigeria, where fertility rate is high.

Through its findings, the study has demonstrated a link between international migration and fertility preferences of women in Benin City, Edo State, Nigeria, by indicating and identifying demographic factors, acculturative mechanism, societal values, attitudes and behaviours that impinge on female fertility intentions. This study informed both our understanding of the determinants of fertility preference in contemporary Benin City and the broader ways in which international migration can help to understand the social processes underlying fertility dynamics.

It is important to note that fertility preference is dynamic and changes from one social milieu to the other as a result of exposure (and or re-exposure) to different fertility values. Women who returned with preference for smaller family size showed propensity to revert to large family size preference which is dominant at place of origin. Since fertility preference constantly changes with social environment, migrants are less likely to become change agents to place of origin on the issue of fertility values as assumed by diffusion theory. Consequently, deliberate intervention would be required to enable returnees retain the smaller family size preference acquired abroad. Length of stay abroad diminishes the effect of disruption (that is, the fertility limiting effect of territorial relocation) on female migrants' fertility desires. This does not in any way suggest the absence of acculturation effect, since, generally, fertility of migrant women still shows similarity to those at destination area. It merely presupposes that, when compared, the fertility preference of women who stayed longer abroad is more likely to be higher than those who stayed for a shorter period. The findings of the study do not support the acculturation school of thought, which suggests that adaption of cultural values increases over time.

Lastly, as anticipated, fertility preference in terms of number of children desired is a predictor of actual fertility outcome.

\section{Conclusion}

The study's assumption that migrants are very likely to revert to the fertility preference prevalent at the place of origin on their return was confirmed, going by some of the results of the research. This conclusion and concern inform the suggestions itemized below:

Policies seeking to promote fertility reduction need to target women generally regardless of whether they have migration experience or not, since fertility preference is shown to predict fertility outcome. This is because the study has provided evidence that migrants will eventually revert to dominant high fertility preference at the place of origin and so, with time, there will be no clear difference between migrants and non-migrants in terms of their fertility preferences and resultant fertility outcomes.

Efforts to promote an official desired family size should be targeted at women generally (migrant and non-migrant) since, as indicated from the study, returnees will normally re-acculturate to dominant fertility preference after their return. As it is today, fertility remains high in Nigeria and stands at 5.7 children on the average; about 1.8 children above nationally desired fertility for the country. High fertility poses serious danger to the quality of life for people and jeopardizes the ability of future generations to meet their own needs (NPC, 2004).

The scientific community should continue to sustain research on impact of migration on various reproductive behaviours with particular focus on the comparison between returnees and rural nonmigrants who, perhaps, constitute the bulk of poor women. For instance, some people are resident in the rural areas that have gone abroad and have returned but are living in places other than the city. These women differ from the participants in this study.

Efforts can also be directed at males since they are major decision-makers in African families. According to Isiugo-Abanihe (1994: |49-|6I), the characteristic male-dominant and patrilineal traditions support large family size and that men's reproductive motivation, to a large extent, affects the reproductive behaviour of their wives. Therefore, factors influencing men's reproductive outcomes and intentions are considered important for fertility transition in Nigeria. This means that the gains achieved through returnees' migration experience, particularly with regard to preference for smaller family size, can be downplayed easily if their male partners retain preference for larger family size. Inter -spousal communication should be encouraged. Male attitudes about population matters should be constantly gauged and shaped in line with preference for small family size. 


\section{References}

Adepoju, A. (2005). Migration in West Africa. A paper prepared for the Policy Analysis and Research Programme of the Global Commission on International Migration. by Human Resources Development Centre. Lagos, Nigeria. Sept 2005.

Adsera, A and Ferrer, A. M. (20I I). Age at Migration, Language and Fertility Patterns among Migrants to Canada. IZA Discussion Paper No. 5552.

Ajaero, C. K; DE Wet, N. (20I7). Life satisfaction and internal migration intention in South Africa. African Population Studies, [S.I.], v. 3I, n. I, sep

Andersson, G. (2004). Childbearing after migration: fertility patterns of foreign-born women in Sweden. International Migration Review 38(2): 747-775.

Attiya, M. (1976). Internal migration, its impact and motives: an empirical study of the characteristics of migrants from the village of Mushairaf to Cairo, $\mathrm{PhD}$ dissertation, in Shams University, Cairo (in Arabic).

Ayiemba, E.H.O. (1990). Migration and urbanization: Kenya's experience since 1948. Proceedings of the international workshop on migration flows in Eastern and Southern Africa. Nairobi. Feb, 1990. 25-28

Banks, J.A. (1954). Prosperity and parenthood: a study of family planning among the Victorian middle classes. London: Routledge \& Kegan.

Bavel V. J, Moreels S, de Putte V. B and Matthijs K. (20lI). Family size and Intergenerational social mobility during the fertility transition: evidence of resource dilution from the city of Antwerp in nineteenth century Belgium. Demographic Research, volume 24, article 14, pages 313-344

Birdsong, D. (1992). Ultimate attainment in second language acquisition. Language 68 (4), 706-755.

Blau, F. D., (1992). The fertility of immigrant women: evidence from high-fertility source countries. In J. B. George and R. B. Freeman (eds.) Immigration and the work force: economic consequences for the United States and source areas. Chicago: University of Chicago Press, pp. 93-I33.

Bleakley, H. \& A Chin, (2010). Age at arrival, English proficiency, and social assimilation among US immigrants. American Economic Journal: Applied Economics, vol. 2(I), pages 165-92.

Bozon, M., E. Lelievre, et al. (200I). Demography of the World's Regions: Situations and Trends. Paris, INED.

Brockmann H., (200I), Girls Peferred? Changing patterns of sex preferences in the two German states, European Sociological Review, 17, pp. 189202.

Burnam, M.A, R.L. Hough, M. Karno, J.I. Escobar and C.A. Telles (1987). Acculturation and lifetime prevalence of psychiatric disorders among Mexican Americans in Los Angeles. Journal of Health and Social Behavior 28 (I): 89-102.

Caldwell, John C. (1982). Theory of fertility decline. Academic Press.

CAPMAS, (1989). Housing and Population Census, 1986. Cairo.

Chattopadhyay, M., White M.J., and Debpuur C. (2006). Migrant fertility in Ghana: selection versus adaptation and disruption as causal mechanisms. Population Studies, Vol. 60, No. 2: 189-203.

Chen J, Hongyan L, and Zhenming X. (2010). Effects of rural-urban return migration on women's Family planning and reproductive health attitudes and behaviour in rural China. Studies in Family Planning. Vol 4I, I: 3।-44

Chiswick, B.R. (|99|), Speaking, reading, and earnings among low-skilled immigrants, Journal of Labor Economics, Vol. 9, No. 2: I49-I70

Fargues, P. (2007). The demographic benefit of international migration: hypothesis and application to Middle Eastern and North African contexts, in International Migration, Economic Development and Policy, ed. by C. "Ozden, and M. Schiff, pp. 161-182. Washington: The World Bank.

Farley, J. E. (1992). Sociology 2nd Edition. Prentice Hall, Englewood Cliffs, New Jersey.

Gabrielli G, Paterno A and White M. (2007). The impact of origin region and internal migration on Italian fertility. Demographic Research, volume 17, Article 24, Pages 705-740

Genereux A. (2007). A review of migration and fertility theory through the lens of African immigrant fertility in France. MPIDR WORKING PAPER WP 2007-008 FEBRUARY 2007

Goldberg, D. (1959). The fertility of two-generation urbanites. Population Studies I2(3): 214-222.

Goldberg, D. (1960). Another look at the Indianapolis fertility data. Milbank Memorial Fund Quarterly 38(I): 23-36.

International Organisation for Migration (IOM), (1995). Migration management training programme. Chapter I. Geneva.

INSEE, (1999). Population: Immigres et etrangers en Ile-de-France. Paris, INSEE.

Isiugo-Abanihe, U.C. (2003). Male role and responsibility in fertility and reproductive health in Nigeria. Centre for population activities and education for development (CEPAED) Ibadan. Ababa

Kirk, D. and Pillet B. (1998). Fertility levels, trends, and differentials in sub-Saharan Africa in the 1980s and 1990s. Studies in Family Planning (New York), vol. 29, No. I, pp. I-22. 
Kulu, H. (2005). Migration and fertility: competing hypotheses re-examined. European Journal of Population 21: 5I-87.

Kulu, H. (2003). Migration and fertility: competing hypotheses re-examined. MPIDR working paper Oct, 2003.

Lindstrom, D. P. and Saucedo, S.G. (2002). The Short and Long-term Effects of U.S. Migration experience on Mexican Women's Fertility. Social Forces, 80, I34I-I 368.

Lindstrom D. P. and Saucedo S G. (2000). "The short and long term effects of US migration experience on Mexican women's fertility." Social Forces 80(4): I34I-I 368.

Masgoret, A-M. and R.C. Gardner (1999). A causal model of Spanish immigrant adaptation in Canada. Journal of Multilingual and Multicultural Development 20 (3), 216-236.

Milewski, N. (2007). First child of immigrant workers and their descendants in West Germany: Interrelation of events, disruption, or adaptation? Demographic Research 17(29): 859-896. www.demographicresearch.org/Volumes/Vol I7/29/default.htm.

National Population Commission (NPC) [Nigeria]. (2004). National policy on population for sustainable development. Abuja, Nigeria: National Population Commission.

$\mathrm{Ng}$, E., and F. Nault. 1997. Fertility among recent immigrant women to Canada, (|99|): an examination of the disruption hypothesis. International Migration 35 (4): 559-80.

Nigeria Demographics and Health Survey. (2008).

National Population Commission (NPC) [Nigeria] and ICF Macro.Nigeria Demographics and Health Survey 2008. Abuja, Nigeria: National Population Commission and ICF Macro. 2009.

Nigeria Immigration Service (NIS) (2009). Information provided by an NIS representative participating in the technical working group established under the National Migration Profile Project, Nigeria.

Odimegwu, C., De Wet, N. Adedini, S. A. Nzimande, N. Appunni, S. Hochfeld, T and Dube, T. (20I7). Family demography in sub-saharan Africa: A systematic review of family research. African Population Studies Vol. 3I, No., (Supp. 2)

Ohagi, E.J.and Isiugo-Abanihe, U.C. (1998). Urbanrural return migration and rural development in the Ideato, Imo State, Nigeria. African Population Studies, I4(2):53-74.
Okali, D., Okpara E. \& Olawoye, J.(200I). The case of Aba and its region, southeastern Nigeria. Ruralurban interactions and livelihood strategies series. Working paper 4. International Institute for Environment and Development (IIED). London

Omondi, C. O. \& Ayiemba, E. H. O.(2003). Migration and Fertility Relationship: A Case Study of Kenya. African Population Studies Vol. 18, No. I, April 2003: 97-II3

Onokerhoraye, A. G. (1993). Population, Immigration and home Studies. The Benin Social Science Series for Africa. Benin City.country ties: what does it mean for Chicago? Indianapolis, Indiana University - Purdue University.

Pessar, P. and S. Mahler (2003). "Transnational Migration: Bringing Gender In." International Migration Review 37(3): 8I2-846.

Ratha D, Mohapatra S, Scheja E. (20II). Impact of migration on economic and social development: a review of evidence and emerging issues. The World Bank Development Prospects Group Migration and Remittances Unit \& Poverty Reduction and Economic Management Network February 201I

Ryder, N.B. (1979). The Future of American fertility. Social problems, Vol. 26, No. 3, Pp. 359-370.

Schaafsma, J., and A. Sweetman (200I). Immigrant earnings: age at immigration matters.

Sharma H.L. (1992). A study of relationship between migration and fertility. Demography India 2I(I):5 I-7.Canadian Journal of Economics 34 (4): 1066-1099.

Stevens, G. (1999). Age at immigration and second language proficiency among foreign-born adults. Language in Society, 28 (4), 555-578.

Toulemon, L. (2004). "Fertility among immigrant women: new data, a new approach." Population and Societies.

United Nations Population Division Department of Economic and Social Affairs (UN DESA) 2015. "Trends in International Migration Stock: The 2015 Revision”. (POP/DB/MIG/Stock/Rev.20I5, Table http://www.un.org/en/development/desa/populati onmigration/data/estimate2/data/UN_MigrantStoc kTotal_2015.xlsx

UNESCO, (2006). Commission on population and development. Thirty-ninth session. 5th \& 6th meetings. 